\title{
LOS FONDOS ARCHIVÍSTICOS COMO FUENTES PARA EL ESTUDIO DE LAS CANCILLERÍAS REALES EN LAS EDADES MEDIA Y MODERNA
}

Vicente Montojo Montojo

Archivo Histórico Provincial de Murcia

\section{RESUMEN:}

La producción documental de las cancillerías hispánicas bajomedievales y los consejos de los Austrias es considerada como objeto de estudio de este artículo desde el punto de vista de la formación de las series documentales y fuentes para la investigación a que dió lugar dicha producción documental en la generación de fondos archivísticos, tales como los registros de la cancillería catalanoaragonesa en el Archivo de la Corona de Aragón, el registro general del sello de Corte de la Corona de Castilla, los libros de cédulas de la Cámara o los libros becerros en las sección de Clero del Archivo Histórico Nacional o en los fondos exentos de Hacienda de los Archivos Históricos Provinciales. PALABRAS CLAVE: Cancillerías, Consejos, Fuentes documentales, Archivos históricos.

\section{ABSTRACT:}

The docummentary production from the Hispanic low-medieval chancilleries and the Habsbourgs's councils is considered the object of study of this article from the point of view of the docummentary series formation as well as sources for the investigation which was the origin of the 
docummentary production for the generation archives files such as the registers from the catalanoaragonesa chancillerie (in the Aragon Crown Archive), the general register from the seal court of Castilla Crown, or also the calfskin books which can be found in the Clerical Section from the Historical National Archive or in the tax-free funds from the Provincial Historical Archives.

KEY WORDS: Chancilleries, Councils, docummentary sources, Historical Archives.

Para antes del surgimiento de las cancillerías ${ }^{1}$, que tuvo lugar en unos territorios ya en la Plena (siglos XI-XIII) y en otros reinos en la Baja Edad Media (siglos XIII-XV), es bien conocido que la función cancilleresca (necesaria siempre) fue ejercida por los escribanos reales o palatinos que acompañaban a los reyes o eran utilizados por ellos: el comes notariorum en la España visigoda o el escribano condal o real de las reducidas curias de los cinco reinos hispánicos medievales: Aragón, Castilla, Cataluña, León y Navarra.

Con la creación de las cancillerías y de otras instituciones o administraciones se dió un proceso de complicación y complejidad de las funciones e instituciones cancilleresca y notarial, surgiendo distintos tipos de oficios y niveles de escribanos, como cancilleres, notarios de los reinos, escribanos reales y numerarios en Castilla y León ${ }^{2}$, o diversos cancilleres, vicecancilleres, protonotarios y escribanos de mandamiento y de registro en los reinos orientales ${ }^{3}$. Los notarios y protonotarios tuvieron en esta época un nivel profesional superior al de los escribanos, que eran burócratas de pluma.

1 Agradezco en primer lugar las sugerencias de los doctores Isabel García Díaz e Ignacio Panizo Santos.

$2 \mathrm{M}^{\mathrm{a}}$ Soterraña MARTÍN POSTIGO, "Las cancillerías reales castellanas. Estado actual de sus estudios", Boletín de la Sociedad Castellonense de Cultura, LVIII (1982), 513547.

3 Ángel CANELLAS LÓPEZ, "Las cancillerías catalano-aragonesas. Estado actual de la cuestión”, y Santos GARCÍA LARRAGUETA, "Estado de la cuestión de las cancillerías y del documento regio navarro", Boletín de la Sociedad Castellonense de Cultura, LVIII (1982), 351-394; Ángel CANELLAS LÓPEZ, "La Cancillería real del reino de Aragón (1035-1134)", y José TRENCHS, "Las escribanías catalano-aragonesas desde Ramón Berenguer IV a la minoría de Jaime I", Folia Budapestina, Zaragoza, 1983; José TRENCHS, "Las cancillerías de la Corona de Aragón y Mallorca desde Jaime I a la muerte de Juan II", Folia Parisiensia, I (1983); José TRENCHS y Francisco M. GIMENO BLAY, La Paleografía y la Diplomática en España (siglo XX), Valencia, 1989. 
Las cancillerías reales, como instituciones políticoadministrativas y documentales, caracterizaron a las administraciones cortesanas de Europa Occidental durante la Baja Edad Media ${ }^{4}$, empezando por la Pontificia ${ }^{5}$, desde el siglo XII, hasta el punto de pasar por ella no sólo la escrituración y validación de los asuntos de orden interno, sino también los de relaciones exteriores, función ésta última que se concretaría, por ejemplo, en las cartas diplomáticas de la Cancillería catalanoaragonesa ${ }^{6}$.

Las cancillerías reales encauzaron la producción documental de las monarquías y sus curias ordinarias ${ }^{7}$ y extraordinarias, es decir, de un régimen administrativo embrionario, como insistiremos más tarde ${ }^{8}$.

Paralelamente, en la Baja Edad Media, la función cancilleresca se fue dividiendo en otras funciones, oficios y organismos burocráticos, tanto de carácter material (gobierno, hacienda, justicia, gracia) como territorial: Consejo Real, Contadurías, Reales Chancillerías, Cámara de Castilla, Consejo de las Órdenes Militares, Consejo de Aragón 9 .

La administración bajomedieval en la que floreció el notariado público era una organización embrionaria y con mezcla de funciones, que no se separaron hasta la época constitucional ${ }^{10}$.

Este carácter embrionario repercutió en la simplificación o el escaso desarrollo de lo que hoy llamamos burocracia, es decir, el pequeño número de oficiales públicos especializados y la corta vertebración orgánica de la administración. Los escribanos formaron gran parte de la administración,

4 Robert-Henri BAUTIER, Chartes, sceaux et chancelleries: Études de diplomatique et de sigillographie médiévales, París, 1990.

5 Tomás MARÍN MARTÍNEZ/José Manuel RUIZ ASENCIO (directores), Paleografía y Diplomática, Madrid, 1988, t. 2, 387-412.

6 Francisco SEVILLANO COLOM, "Apuntes para el estudio de la Cancillería de Pedro IV el Ceremonioso", Anuario Histórico del Derecho Español, XX (1950), 137-241.

7 "De la Curia Regia nos vendrán los archivos de Patronato Real y Chancillerías" dice Antonio MATILLA TASCÓN, "Historia de los Archivos españoles y sus fondos documentales", Análisis e investigaciones culturales, 18 (1984), 11-29, cfr. 14.

8 Las cancillerías encauzaron la producción documental de las curias reales, lo que fue más patente en la cancillería francesa que en las hispánicas. Ver: Olivier GUYOTJEANNIN/ Jacques PYCKE/Benoît-Michel TOCK, Diplomatique médiévale, s.l., 1993.

9 Sobre el valor de la documentación cancilleresca para el estudio de las relaciones internacionales ver: Carlos LÓPEZ RODRÍGUEZ, "La dimensión internacional de los archivos estatales", De la brújula a internet. Los archivos estatales españoles, Madrid, 2000, 213-296, cfr. 216-247.

10 Juan Alfonso SANTAMARÍA PASTOR, Fundamentos de derecho administrativo, Madrid, 1991. 
hasta el punto de que ellos escrituraban tanto los autos o expedientes de gobierno, como los procesos judiciales, todo ello en los diversos tipos de administración, fuera la central (la Corte o las curias), la territorial (virreinatos y adelantamientos, veguerías, gobernaciones y corregimientos) o la municipal (concejos). De los tres tipos de oficios que consideró Tomás y Valiente ${ }^{11}$ como componentes de la administración del Antiguo Régimen (los de jurisdicción, los de dineros: contadores, depositarios, etc; y los de pluma), los escribanos pertenecían a estos últimos, pero eran ellos los que redactaban los documentos de los demás, de aquí la importancia de su actividad, que debemos conocer bien.

Para más adelante nos consta que existía la Cancillería como institución de la administración real castellana en el siglo XVI con un nuevo carácter sobreañadido, quizá por influencia germánica, el de asesoramiento diplomático en el caso de Chiévres o en el de Gattinara ${ }^{12}$, aunque este último también tuvo la función de la custodia del sello del Consejo de Indias, en lo que no se alejaría de la tradición bajomedieval del oficio; pero por entonces (hacia 1525) la Cancillería dejaría de destacar en el ámbito de las relaciones internacionales, pues se impuso el régimen polisinodial o sistema de consejos y con él lo hizo el Consejo de Estado ${ }^{13}$, conservando la Cancillería su función tradicional de validación de documentos ${ }^{14}$.

11 Francisco TOMÁS Y VALIENTE, Gobierno e instituciones en la España del Antiguo Régimen, Madrid, 1982, 158-162.

12 John HEADLEY, The Emperor and his Chanceller. A study of the imperial chancillery under Gattinara, Cambridge, 1984, 40.

13 “A partir de la desaparición de Chièvres, ningún personaje (salvo Cobos) influiría tan ampliamente en la voluntad de Carlos V. Ciertamente a través de la cancillería se encauzaba la política de la Monarquía y se nombraban los oficiales, pero la reforma efectuada en el gobierno, en 1523, apostando por una administración basada en consejos amplió las facultades e importancia de los secretarios al recaer sobre ellos la gestión del gobierno, lo que implicaba el trato directo con el monarca para recibir las órdenes pertinentes": José MARTÍNEZ MILLÁN/Carlos DE CARLOS MORALES (directores), Felipe II(1527-1598). La configuración de la monarquía hispana, Salamanca, 1998, 27. Es la tesis mantenida anteriormente por Francisco TOMÁS Y VALIENTE, Los Validos en la Monarquía Española del siglo XVII. Estudio institucional, Madrid, 1982.

$14 \mathrm{M}^{\mathrm{a}}$ Soterraña MARTÍN POSTIGO,"La Cancillería castellana en la primera mitad del siglo XVI", Hispania, XXIV (1964), 348-367 y 509-551; "Aportación al estudio de la Cancillería Real castellana en la segunda mitad del siglo XVI", Hispania, XXVII (1967), 383-404; "La Cancillería Real castellana en el siglo XVII", Cuadernos de Historia de España (1987), 123-195. 
Para ser realistas, nos interesan las cancillerías como organismos controladores de documentos reales y como productores del registro del sello de la corte y de privilegios.

\section{1.- Relaciones entre escribanías y cancillerías durante la Baja Edad Media.}

Nuestras reflexiones parten de una experiencia, que es el hecho de que los fondos documentales notariales de los archivos históricos provinciales, notariales y municipales han de ser comprendidos en el contexto histórico en el que fueron producidos o se formaron y del que por otra parte son un buen testimonio. Su origen más o menos remoto estaría en las cancillerías reales, de las que el notariado sería una prolongación, pues la organización cancilleresca se fue complicando sucesivamente mediante la proliferación de notarías (notarios mayores de los reinos) ${ }^{15}$ y escribanías (escribanos de cámara, escribanos reales) que se produjo desde la Plena Edad Media (siglos VIII-XIII) ${ }^{16}$.

Durante la Baja Edad Media la existencia de diversas escribanías en el Reino de Murcia ${ }^{17}$, teniendo en cuenta su incorporación a Castilla y asimismo su ocupación posterior por Jaime II de Aragón(1296-1304), hace que se haya de tener en cuenta las relaciones de estas escribanías con las cancillerías castellanoleonesa y catalanoaragonesa. Estas cancillerías se convierten en punto de referencia para las escribanías situadas en el Reino de Murcia puesto que recibían documentos procedentes de las mencionadas cancillerías y las escribanías iniciaban el trámite con documentos que a continuación eran dirigidos a las cancillerías y despachados por ellas, como las renuncias de los regidores o los poderes de los concejos y otras instituciones para obtener las confirmaciones de sus privilegios. Por lo tanto, hay que considerar la producción documental de las cancillerías como fondos documentales interesantes para la investigación regional. Las cancillerías reales fueron instituciones, además, que han de entenderse en el marco de carácter

15 El Reino de Murcia se adscribió al notario mayor del Reino de Toledo: Gonzalo. MARTÍNEZ DÍEZ, "Génesis histórica de las provincias españolas", Anuario Histórico del Derecho Español, LI (1981), 523-593.

16 Ma Jesús ÁLVAREZ COCA GONZÁLEZ, "La fe pública en España. Registros y notarías. Sus fondos. Organización y descripción", Boletín de la Asociación Nacional de Archiveros, Bibliotecarios, Arqueólogos y Documentalistas, 1-2 (1987), 1-67.

17 Miguel RODRÍGUEZ LLOPIS, "La escritura y el poder. La emisión de documentos en la sociedad murciana bajomedieval”, Áreas, 9 (1988), 11-24. 
embrionario de las cortes o curias regias medievales, en cuya evolución hay que distinguir dos etapas (altomedieval y bajomedieval) en torno a la recepción romanista, que se inició primero en las universidades y se dio en la legislación posteriormente, en el siglo XIII ${ }^{18}$.

Los archivos de la Corona de Aragón, General de Simancas e Histórico Nacional son considerados los centros archivísticos básicos para el estudio de las cancillerías de los reinos hispánicos medievales. No obstante, aceptando la validez de esta consideración, también hay que decir que pueden servir muchos otros archivos, de distintos tipos. Por ejemplo, se ha dicho que para la Alta Edad Media destacan los archivos capitulares de Oviedo y León y el del monasterio benedictino de San Pelayo, el capitular de León con una importante colección de documentos reales desde el siglo VIII ${ }^{19}$, pero estas afirmaciones no nos sirven para la España meridional, que permaneció bajo dominio musulmán hasta el siglo XIII.

Para esta última zona geográfica, la España meridional habrá que tener en cuenta otros archivos, como los de catedrales, colegiatas, conventos, concejos, universidades, la Mesta ${ }^{20}$.

En el caso de Murcia habría que destacar los fondos documentales de los archivos municipales, como los de Murcia, Lorca y Cartagena, o algunos eclesiásticos, como el de la Catedral de Cartagena (situada en Murcia), o el conventual de Santa Clara ${ }^{21}$.

18 Antonio PÉREZ MARTÍN (edición), España y Europa, un pasado jurídico común (Actas del Y Simposio Internacional del Instituto de Derecho Común, Murcia, 26-28 de marzo de 1985), Murcia, 1986.

19 Rosana DE ANDRÉS DÍAZ, "El Estado: documentos y archivos”, Enciclopedia de Historia de España, VII, Madrid, 1993, 85-145, cfr. 87.

20 Blas CASADO QUINTANILLA, Documentación real en el archivo del concejo abulense, 1475-1499, Ávila, 1993. Severiano HERNÁNDEZ VICENTE, "El Archivo de la Universidad de Salamanca", Boletín de la Asociación Nacional de Archiveros, Bibliotecarios, Arqueólogos y Documentalistas, 3-4 (1997), 199-209. J. M. FERNÁNDEZ POMAR, "Catálogo de 152 documentos de la Mesta, del Archivo Histórico Nacional", Archivos Leoneses, 68 (1980), 329-384.

$21 \mathrm{M}^{\mathrm{a}}$ Ángeles JOVER CARRIÓN, Documentos Murcia-Sevilla (s. XIII a s. XVII)): Catálogo de la Exposición, Murcia, 1992. M Ángeles JOVER CARRIÓN, El papel de nuestra historia. Archivo Municipal de Murcia, Murcia, 2003. Manuel MUÑOZ CLARES/Eduardo SÁNCHEZ ABADÍE, El papel de nuestra historia. Archivo Municipal de Lorca, Murcia, 2000. Cayetano TORNEL COBACHO, Las fichas de catálogo de documentos textuales de archivo. Catálogo de Documentos Medievales del Archivo Municipal de Cartagena, Cartagena, 1990. Pascual GALINDO ROMEO, "Reconstitución del Archivo del 
A la hora de conocer la producción documental de las cancillerías reales ha de identificarse no sólo la tipología diplomática, sino también la serie documental $^{22}$ a que ha dado lugar la mencionada producción documental cancilleresca.

El diploma, por ejemplo, ha sido considerado tradicionalmente la principal fuente para el estudio de las cancillerías, en lo que se refiere a su composición o a su producción documental, atendiéndose recientemente a aspectos más formales, como el documento pintado en su evolución desde el privilegio signado hasta el privilegio rodado ${ }^{23}$. No hay que olvidar, sin embargo, otros documentos, como los de régimen interno, entre los que se cuentan los registros y otros tipos documentales.

a) Fuentes en la Corona de Aragón.

La documentación real catalana se conservó primero en el monasterio sanjuanista de Sijena, pasando después al de San Juan de la Peña, el Temple y el Palacio Real de Barcelona. La primera referencia a un archivo real de Barcelona es de 1180, aunque este archivo fue realmente instituido por Jaime II en 1318, mientras que su primer archivero fue designado por Pedro IV el Ceremonioso en 1346. Este monarca dictó las primeras ordenanzas del archivo real de Barcelona, en $1384^{24}$.

Es en el Archivo de la Corona de Aragón donde se conserva el mayor volumen documental para la investigación sobre la Cancillería de los soberanos de Cataluña y de Aragón, surgida hacia 1218, a principios del reinado de Jaime I, pero existen también fondos documentales cancillerescos en el Archivo del Reino de Valencia, desde principios del siglo XV, así como

Monasterio de Santa Clara la Real de Murcia", en Actas de las I Jornadas de Metodología aplicada a las Ciencias Históricas, V, Santiago de Compostela, 1975, pp. 61-74. Isabel GARCÍA DÍAZ (edición), Documentos del Monasterio de Santa Clara, Murcia, 1997.

22 Antonia HEREDIA HERRERA, Archivistica General. Teoría y práctica, Sevilla, 1993; COMISIÓN DE TERMINOLOGÍA DE LA DIRECCIÓN DE ARCHIVOS ESTATALES, Diccionario de Terminología Archivística, Madrid, 1993, 49-52.

23 Elisa RUIZ GARCÍA, "Claves del documento artístico bajomedieval en Castilla", $E l$ documento pintado: Cinco siglos de arte en manuscritos, Madrid, 2000, 23-44.

24 Rafael CONDE Y DELGADO DE MOLINA, Las primeras ordenanzas del Archivo Real de Barcelona, Madrid, 1993. 
en el Archivo del Reino de Mallorca y en otros archivos de Madrid y Nápoles, y lo hubo en el Archivo Real de Zaragoza ${ }^{25}$. En lo que se refiere a Murcia hay algunos trabajos que han utilizado estos documentos ${ }^{26}$.

También podemos señalar que en el Archivo de la Corona de Aragón se conserva la documentación condal o real más antigua, incluso desde el punto de vista del territorio carolingio 27 .

La información sobre la organización interna de la Cancillería catalanoaragonesa se halla muy dispersa, pudiéndose concretar en cinco grupos:

1) Ordenanzas.

2) Capítulos de Cortes: Regulaban sobre todo las funciones de la administración de justicia, encomendadas a cancilleres, vicecancilleres y regentes de la Cancillería.

3) Nombramientos de los oficiales de la misma, que no siempre se encuentran, a causa de las irregularidades de la documentación (escasez comprensible de pergamino, anormalidades en los registros). Dichos nombramientos han de buscarse en los registros titulados "officialium", pues hay que tener en cuenta que los registros de la Cancillería aragonesa se dividían en: curiae, officialium, diversorum y commune ${ }^{28}$, o más adelante también en notariorum, etc ${ }^{29}$.

4) Listas de oficiales de la Escribanía real, en la sección Real Patrimonio.

5) Datos sueltos muy dispersos, que muestran la actividad de diversos oficiales.

25 Rafael CONDE Y DELGADO DE MOLINA, "Archivos y archiveros en la Edad Media Peninsular", Historia de los archivos y de la archivística en España, Juan José GENERELO y Ángeles MORENO, coordinadores, Valladolid, 1998, 13-28, cfr. 18-26; y "Los archivos de la monarquía hispánica", Felipe II y el Mediterráneo, Ernest BELENGUER CEBRIÀ, coordinador, Madrid, 1999, v. 3, 193-211, cfr. 20-24.

26 Juan TORRES FONTES, Colección de Documentos para la historia del reino de Murcia, Murcia, 1963/ 1969/ 1973, I-III. Miguel RODRÍGUEZ LLOPIS, "La expansión territorial castellana sobre la cuenca del Segura (1235-1325)", Miscelánea Medieval Murciana, XII (1985).

27 Olivier GUYOTJEANNIN/ Jacques PYCKE/Benoît-Michel TOCK, op.cit., cfr. 357.

$28 \mathrm{M}^{\mathrm{a}}$ Jesús ÁLVAREZ-COCA GONZÁLEZ, “Aragón en la Administración Central del Antiguo Régimen. Fuentes en el Archivo Histórico Nacional”, Ius fugit, 2 (1993), 9-41, cfr. 16. Ignaci BAIGES JARDÍ, Els registres officialium a la Cancillería de Jaume II. Barcelona, 1990.

29 Beatriz CANELLAS/Alberto TORRA, Los registros de la Cancillería de Alfonso el Magnánimo, Madrid, 2000. 
En el Archivo de la Corona de Aragón se conservan los registros de las escribanías condal de Barcelona y real de Aragón y de la Cancillería real de la Corona de Aragón, un preciado tesoro que ha sido comparado en importancia con la serie análoga de los pontífices, en el Archivo Vaticano.

Con Ramón Berenguer II (siglo XI) habría probablemente ya un notario, pero la serie de pergaminos de la sección Cancillería se remonta a Wifredo el Velloso (finales del siglo IX) ${ }^{30}$. Además de la serie de pergaminos, consta esta sección de unos 6700 registros desde el siglo XIII hasta el XVIII, redactados por los escribanos de registro, ordenados por reinados y años, que continúan en los registros de la Real Audiencia (siglo XVIII), pues con los Decretos de Nueva Planta desapareció la Cancillería aragonesa ${ }^{31}$.

Los registros se iniciaron por los años 1253-1259 del reinado de Jaime I, es decir, en torno al Tratado de Corbeil con Luis IX de Francia, y acabaron en el de Isabel II, abarcando por tanto siete siglos y siendo muy escasas sus lagunas en relación con el conjunto total. Están clasificados por materias dentro de cada reinado, aunque con Jaime I puede decirse que no hubo clasificación alguna y sólo a medida que se perfeccionó la organización interna de la Cancillería mejoró también la clasificación metódica de los volúmenes. Son más abundantes los de los reinados de Jaime II, Pedro IV, Alfonso V y Reyes Católicos. Existen algunos registros en otros archivos, como el de la Real Academia de la Historia, que conserva tres del de Pedro IV.

La conservación de los registros de la Cancillería catalanoaragonesa en algunos de los reinos sería ocasión de la institución de los archivos reales de Valencia (en 1419) y Aragón (en 1461), este último desaparecido en uno de los sitios de Zaragoza por las tropas francesas, en la Guerra de Independencia $^{32}$.

La Cancillería navarra, surgida como la catalanoaragonesa en el siglo XIII, tuvo sin embargo un desarrollo menor en cuanto a composición, limitándose ésta a un canciller y un vicecanciller y quizá a un protonotario. Como puede observarse en la serie documental del Registro del Sello de la sección Gobierno y Administración del Archivo General de Navarra, no ha

30 Federico UDINA MARTORELL, El archivo condal de Barcelona en los siglos IXX. Estudio crítico de sus fondos, Barcelona, 1951.

31 Rosana DE ANDRÉS, ob.cit., cfr. 88.

32 Rafael CONDE Y DELGADO DE MOLINA, "Archivos y archiveros en la Edad Media Peninsular", 25-26. 
sobrevivido sino sólo un registro del sello y del reinado de Isabel II (de los años 1834-1842), siendo en cambio más abundante la constancia de las actividades de registro y sellado en la serie documental de Procesos del Archivo General de Navarra ${ }^{33}$.

b) Fuentes en los reinos occidentales.

La información sobre la organización interna de la Cancillería castellanoleonesa hay que buscarla asimismo entre ordenamientos y capítulos de cortes, además de en las Partidas o en los diplomas originales. Hay también documentación muy específica, que ha sido estudiada, como se observa en los trabajos de la profesora Martín Postigo, en las cuentas y títulos de quitaciones de Corte, es decir, las retribuciones de los oficios de la curia real, distintas estas últimas (las quitaciones) de las raciones que se daban a los oficiales de la $\mathrm{Casa}^{34}$.

Existieron también registros en la Corona castellanoleonesa, siendo regulados por primera vez en las Partidas de Alfonso X el Sabio, pero a diferencia de las cancillerías catalana y aragonesa, de la que ha quedado un fondo documental, de la castellana no han quedado registros hasta finales del siglo $\mathrm{XV}$, por lo que para su estudio ha de recurrirse a los documentos originales (como los pergaminos) de las secciones Patronato Real, colección inicial del Archivo General de Simancas ${ }^{35}$; las secciones Clero, Órdenes Militares y Códices del Archivo Histórico Nacional, o a los archivos capitulares, monacales, municipales, etc.

Hubo disposiciones sobre estos registros en las Partidas y en diversas Cortes. En las Cortes de Valladolid de 1299, por ejemplo, se dispuso que los registros de Castilla y los de León los tuvieran los respectivos notarios mayores de tales reinos ${ }^{36}$.

$33 \mathrm{M}^{\mathrm{a}}$ Isabel OSTOLAZA ELIZONDO, "Las cancillerías y el documento regio navarro: estado de la cuestión", Boletín de la Sociedad Castellonense de Cultura, 58 (1982), 395-469; "Cancillería y registro de los documentos públicos en Navarra durante la etapa de los Austrias”, Príncipe de Viana, 214 (1998), 433-446; Gobierno y Administración del Reino de Navarra bajo los Austrias, Pamplona, 1999.

$34 \mathrm{M}^{\mathrm{a}}$ Soterraña MARTÍN POSTIGO, La Cancillería castellana de los Reyes Católicos, Valladolid, 1959. Miguel Ángel LADERO QUESADA, La Hacienda Real de Castilla en el siglo XV, La Laguna, 1973, cfr. 53.

35 Francisco Javier ÁLVAREZ PINEDO/José Luis RODRÍGUEZ DE DIEGO, Los Archivos españoles. Simancas, Barcelona, 1993.

36 José Luis RODRÍGUEZ DE DIEGO, Instrucción para el gobierno del Archivo de Simancas (año 1588), Madrid, 1989. 
Pero estas disposiciones respecto al registro del sello no se cumplieron hasta la segunda mitad del siglo XV, época en que el oficio de canciller era ya honorífico (lo ostentaban los arzobispos de Toledo y Santiago) y sus funciones habían pasado a los secretarios reales y a los lugartenientes del canciller mayor en las Reales Chancillerías. Entre estos secretarios que llevaban el sello secreto destacaron Fernando de Zafra, Fernán Álvarez de Toledo y Gaspar de Gricio.

Se trata del sello de Corte (sello mayor de placa, y no de plomo) ${ }^{37}$ regulado en las Cortes de Madrigal de 1476 y en las de Alcalá de Henares de 1498, que dispusieron que el registrador tomase registro horadado de cada carta y provisión. El registro no incluyó las cédulas ni los albalaes, que no llevaban sello, aunque en la Cámara de Castilla sí se llevaba registro de las cartas de merced. Anteriormente, las Cortes de Toro de 1371 habían ordenado la creación de registros de cámara separados de los de justicia y su entrega al camarero para guardarlos en los tesoreros ${ }^{38}$.

Estos registros de cámara o libros generales se conservan en el Archivo General de Simancas (246 libros de los años 1494 a 1671) y en el Archivo Histórico Nacional (144 libros, de 1671 a 1833), pertenecientes a la Secretaría de Gracia y Justicia de la Cámara de Castilla, creada en $1717^{39}$.

Tampoco recogía el Registro del Sello privilegios en pergamino (llevaban sello de plomo y de ellos se tomaba razón en la Contaduría de Hacienda), ni documentos emanados de organismos con sello propio: chancillerías, audiencias y algunos Consejos, a excepción de los de Castilla, Inquisición, Aragón, Órdenes (hasta mediados del XVI) u otros ${ }^{40}$. Se trata, en el Archivo General de Simancas, de 2.400 legajos desde 1475 hasta 1689 y cada legajo lleva los registros de un mes. Están catalogados desde 1475 a

37 Filemón ARRIBAS ARRANZ, Sello de placa de las cancillerías regias castellanas, Valladolid, 1941.

38 José Luis RODRÍGUEZ DE DIEGO, Instrucción para el gobierno del Archivo de Simancas, op.cit.

39 Ma Jesús ÁlVAREZ-COCA GONZÁlEZ, "La Cámara de Castilla: Secretaría de Gracia y Justicia. Problemas archivísticos e investigación histórica", El Tercer poder: Hacia una comprensión histórica de la justicia contemporánea española, J.M. SCHÖLZ editor, Frankfurt am Main, 1992, 1-32, cfr. 5.

40 Filemón ARRIBAS ARRANZ, "Los registros de la Cancillería en Castilla", Boletín de la Real Academia de la Historia, CLXII (1968), 171-200 y CLXIII (1968), 143-162. 
1498. En el Archivo Histórico Nacional se conserva su continuación, desde 1690 hasta $1893^{41}$.

Con los Reyes Católicos se considera a veces que termina el período cancilleresco del bajo medievo, iniciado con Alfonso X, pero la Cancillería real continuó funcionando, aunque los cambios ocurridos en la Edad Moderna no fueron muchos.

La investigación sobre las cancillerías tiene dos ámbitos desde los que se puede abordarla en lo que se refiere a su producción documental. Si bien esta producción tenía un origen unitario, considerando como tal la institución, por contraste, hay que considerar también la pluralidad de destinatarios, lo que nos puede servir de orientación para la búsqueda de fuentes documentales. Los fondos archivísticos de las cancillerías reales guardan la documentación que podríamos llamar de organismo o sujeto productor de un modo concreto, mediante registros, que sirven para control interno, mientras que las instituciones destinatarias de los documentos emitidos por las cancillerías los reciben y conservan de otro modo distinto, en forma de cartularios y de libros de títulos o becerros ${ }^{42}$.

La documentación de las secciones de Clero del Archivo Histórico Nacional nos puede servir de ejemplo, pues se compone de algunas series documentales que tienen numerosas procedencias institucionales, tales como monasterios, catedrales, colegiatas, parroquias, cofradías, oratorios, ermitas $^{43}$. Las propiedades y rentas de estas instituciones se convirtieron en bienes nacionales por obra de las desamortizaciones y los documentos incautados a las instituciones eclesiásticas pasaron a los archivos de

$41 M^{a}$ Jesús ÁlVAREZ-COCA, "La Cámara de Castilla. Secretaría de Gracia y Justicia...”, ob.cit., 25-26.

42 Sobre estos términos: Olivier GUYOTJEANNIN/L. MORELLE/M. PARISSE (editores), Les cartulaires. Actes de la Table Ronde orgganisée par L'Ecole National des Chartes, París, 1993. COMMISSION INTERNATIONALE DE DIPLOMATIQUE/M ${ }^{\mathrm{a}}$ Milagros CÁRCEL ORTÍ (editora), Vocabulaire international de la Diplomatique, Valencia, 1994. J.M. RUIZ ASENCIO, "Cartulario", Diccionario de Historia Eclesiástica de España, I (1972), 368-370.

43 De la actual Región de Murcia se conserva documentación de jesuitas de Caravaca, Cartagena, Lorca y Murcia, carmelitas de Caravaca, mercedarios calzados de Moratalla o Sierra de Benamor y trinitarios calzados de Murcia: [Archivo Histórico Nacional], Inventario de procedencias, Valladolid, 1924. Ver sobre esta sección: Luis Miguel DE LA CRUZ HERRANZ, "La Sección de Clero del Archivo Histórico Nacional", Juan Carlos GALENDE DÍAZ (Coord.), II Jornadas Cientificas sobre Documentación de la Corona de Castilla (ss. XIII-XV), Madrid, 2003, 373-432. 
Hacienda. Algo muy parecido sucedió con los documentos de la sección Órdenes Militares del Archivo Histórico Nacional, de la sección de Monacals o Clero del Archivo de la Corona de Aragón, y del Fondo Exento de Hacienda de los archivos históricos provinciales ${ }^{44}$. En todas estas secciones de archivo se contiene documentación recibida de numerosas instituciones, muy abundante en lo que se refiere a los siglos XIV y XV, y en ellas se encuentran bastantes documentos emitidos por las cancillerías reales ${ }^{45}$.

Es importante, sin embargo, atender a las formas de su conservación, pues para estas instituciones los diplomas o los privilegios, fueran signados o rodados, o las cartas de privilegio y confirmación, constituyeron títulos, ya fueran títulos de propiedad o pertenencia, ya de jurisdicción, de inmunidad, tales como privilegios fiscales o judiciales.

Con las incautaciones de bienes eclesiásticos y de otras procedencias (carlistas) de las desamortizaciones estos documentos fueron también títulos de propiedad o pertenencia para Hacienda, que para demostrar tales propiedades y obtener sus rentas (juros, censos, foros, arrendamientos) hubo de conservar la documentación.

Por otra parte, la necesidad de esta conservación tan característica de las edades media y moderna tuvo su especificidad diplomática, pues las instituciones eclesiásticas, como también la nobleza y otros particulares, con estos títulos formaron cartularios, becerros, tumbos, capbreus y otros tipos de los llamados códices diplomáticos por los diplomatistas ${ }^{46}$. Según Floriano “el registro es colección de textos del autor, mientras que el cartulario lo es del destinatario" 47 .

44 Vicente MONTOJO MONTOJO, "La Intendencia de Provincia de Murcia y sus contadurías: institución y documentación fiscal en Murcia (1749-1849)", Murgetana, 94 (1997), 89-106.

$45 M^{a}$ Jesús ÁLVAREZ-COCA GONZÁLEZ, "El Consejo de las Órdenes Militares", Cuadernos de Historia Moderna, 15 (1994), 297-323, y "La Orden de Montesa: Una jurisdicción especial en el Antiguo Régimen. Aproximación a la organización de la documentación judicial del Archivo Histórico Nacional”, La Administración de Justicia en la Historia de España. Actas de las III Jornadas de Castilla-La Mancha sobre Investigación en Archivos (Guadalajara: 11-14 de noviembre de 1997), Guadalajara, 1999, 457-491.

46 Sobre los capbreus ver: Manuel MARTÍNEZ SÁNCHEZ (Comp.), Estudios sobre rentas, fiscalidad y finanzas en la Cataluña bajomedieval, Barcelona, 1993.

47 Antonio C. FLORIANO CUMBREÑO, Curso General de Paleografía y Diplomática españolas, Oviedo, 1946, 240-245. 
Sin embargo, el hecho es que estos libros no incluyen únicamente copias, sino también originales. Así, en el Archivo Histórico Provincial de Murcia, dentro del Fondo Exento de Hacienda ${ }^{48}$ podemos encontrar algunos originales en los libros becerros del Monasterio de San Pedro de la Ñora, o en los libros de censos de la Inquisición, como también en los protocolos del fondo notarial. En el primer caso, el del Monasterio jerónimo de San Pedro de la Ñora, se puede observar la existencia de la legitimación de un hijo bastardo mediante real provisión de Carlos $\mathrm{I}^{49}$, de una carta de confirmación por Felipe IV de un privilegio del siglo XIII ${ }^{50}$, o de diversos documentos notariales, como testamentos y codicilos del siglo $\mathrm{XV}^{51}$.

En los protocolos notariales, que son en realidad registros de escrituras públicas de escribanos, hay asimismo numerosas provisiones y cédulas reales, algunas cartas de confirmación de privilegios, además de otros documentos realzados mediante un tratamiento más solemne y soporte en pergamino ${ }^{52}$.

La conservación de documentos originales producidos por las cancillerías en becerros monásticos y conventuales o en registros notariales quizá pueda relacionarse con otras agrupaciones documentales de algunos archivos, como son las de patronato y de patrimonio.

La sección de Patronato Real del Archivo General de Simancas, por ejemplo, ha sido considerada una colección, un auténtico tesoro de documentos, prototipo de archivo medieval. Algo parecido podríamos decir de los diplomas y de los códices diplomáticos de otros archivos, que fueron conservados en relación con uno o varios patronatos. En cuanto a los libros becerros y tumbos de numerosos archivos hay también que añadir que se trata de documentos reunidos para la administración del patrimonio adquirido, ya

48 Vicente MONTOJO MONTOJO, Inventario del Fondo Exento de Hacienda (Archivo Histórico Provincial de Murcia), Murcia, 1998, 27-30.

49 Archivo Histórico Provincial de Murcia (AHPM), Fondo Exento de Hacienda, libro n. 3 , n. 11 .

50 AHPM, Fondo Exento de Hacienda, libro n. 5, nn. 1 y 2.

51 Así en el AHPM, Fondo Exento de Hacienda, libro n. 2 (libro becerro n. 1 del Monasterio citado), se encuentran los testamentos del bachiller Pedro Abellán (n. 2, año 1493); doña María de Vozmediano, mujer de don Manuel de Arróniz (n. 3, 1507) y de su marido, regidor de Murcia (n. 4, 1509); doña Beatriz Manuel, viuda de Francisco de Soto (n. 5, 1515), y de doña María de Arróniz, viuda de Diego de Villaseñor y mujer de don Pedro Calvillo Avilés (n. 17, 1476).

52 El censo de Rodrigo Escortel sobre 3 cuartos de agua y tierras en el pago de Beniçad, huerta de Murcia, del año 1493 (AHPM, Fondo Notarial, Protocolo n. 3395, fs. 131r-134v). 
como títulos, o como resultantes de la administración: arrendamientos, censos, cuentas. Un ejemplo de este tipo de documentos podría ser el Libro Becerro de las Behetrías (o Libro Becerro de las Merindades de Castilla), del año 1352, conservado su original en el Archivo General de Simancas, sección de Patronato Real, puesto que su realización fue el resultado de pesquisas o averiguaciones de los derechos y las rentas del rey y los hidalgos castellanos en las merindades menores de Castilla ${ }^{53}$, lo que podría además sugerirnos una comparación con algunos capbreus catalanes.

De aquí se podría deducir que también las cancillerías y por lo tanto las escribanías, o el notariado, son tan útiles como fuente para el estudio de la vida social y económica, como para las relaciones diplomáticas. Una de las razones quizá pudo ser el fuerte carácter patrimonial de las monarquías feudal y absoluta en todos sus ámbitos. En los privilegios de las cancillerías encontraremos muchos títulos de concesiones de tierras, oficios, rentas, distinciones, es decir, testimonios de la enajenación patrimonial tan acentuada y característica desde la Alta Edad Media hasta el final de la Edad Moderna. La gestión o administración de este patrimonio, fuera real o condal, requirió también desde el principio una delegación en oficiales reales, que se hizo más complicada a lo largo de la edades Media y Moderna.

2. La organización cancilleresca bajo los Reyes Católicos y los Austrias: proliferación de consejos reales y diversificación de escribanías.

La concentración de poder característica del periodo de formación de la monarquía absoluta conllevó la formación de una nueva administración (régimen polisinodial) y un nuevo tipo de archivo, denominado "arsenal de poder" por algunos teóricos de la archivística.

Según un experto archivero, la multiplicación y homogeneidad de fondos documentales de la administración central a partir del último tercio del siglo XV se debió a los siguientes factores:

- Centralización del poder: la composición del Consejo Real deja de ser estamental.

- Sedentarización de la corte: permite la estabilidad y concentración de archivos.

53 Gonzalo MARTÍNEZ DÍEZ, Libro Becerro de las Behetrías, León, 1981, 87-104. 
- División de la materia administrativa: proliferación de instituciones.

- Configuración orgánica de la administración ${ }^{54}$.

Hay, sin embargo, que replantear algunos procesos históricos que se dan como definitivos.

El gobierno, que estuvo siempre ligado a la justicia, se ejerció desde la Baja Edad Media a través de órganos colegiados (consejos) y delegados unipersonales (adelantados, virreyes, corregidores, gobernadores) que asumieron ámbitos territoriales y competenciales muy variados. En los siglos XVI y XVII este sistema se extendió a los numerosos territorios de la Monarquía Hispánica en diferentes zonas europeas, como Aragón, Italia, Flandes y Portugal, por medio de los consejos y secretarías provinciales y, como organismos tendencialmente centralizadores, los consejos de Estado y Guerra $^{55}$.

Este proceso de centralización se concretó en la formación de unos consejos (Hermandad, Inquisición, Aragón, Órdenes Militares y Cruzada bajo los Reyes Católicos), unas chancillerías y audiencias y unos adelantamientos, gobernaciones y corregimientos, si bien esta estructura no diferenciaba las materias gubernativa y judicial, pues consejos y tribunales tenían funciones gubernativas y judiciales, y adelantados, gobernadores y corregidores también militares y fiscales.

La estructura institucional de este régimen político, denominado a veces polisidonial, fue más complicado de lo que parece. No se limitó a los diversos consejos, sino que derivó en la formación de numerosas juntas, cuyos nombres son más ilustrativos que los de los consejos en relación a la evolución de la estructura orgánica de la administración central. Así la Audiencia de Descargos de Isabel la Católica y reyes posteriores, o las Juntas de Reformación y de Competencias, que identifican bien el período de gobierno del Conde Duque de Olivares, o la Junta de Alivios, que sería una muestra de la política hacendística del reinado de Carlos $\mathrm{II}^{56}$.

54 José Luis RODRÍGUEZ DE DIEGO, “Archivos de la Administración Central desde el siglo XV al XX”, Irargi: Revista de Archivística, 2 (1989), 37-101.

55 M $^{\mathrm{a}}$ Pilar CASTRO MARTOS, "El Archivo del Consejo de Estado", Boletín de la Asociación Nacional de Archiveros, Bibliotecarios, Arqueólogos y Documentalistas, 1 (1996), 119-138.

56 Juan A. SÁNCHEZ BELÉN, "La Junta de Alivios de 1669 y las primeras reformas de la regencia”, en Espacio, Tiempo y Forma (H ${ }^{\mathrm{a}}$ moderna), 4 (1989), 639-668. 
Otro problema es la evolución de la burocracia en los siglos XVI al XVIII, que creció con la multiplicación de los consejos (secretarios, relatores y escribanos de consejos, juntas, chancillerías, audiencias y corregimientos) pero de forma modesta, de tal modo que estos oficiales, que son llamados mediadores ${ }^{57}$, fueron escasos y tenían un carácter ambivalente: defendían los intereses del rey, pero también los de las oligarquías locales a las que se dirigían y cuya colaboración necesitaban.

La corte o administración central mezclaba, por lo tanto, funciones gubernativas y judiciales, y se compuso de órganos consultivos especializados por la materia: Inquisición (1488), Órdenes (1495), Guerra (1518), Cámara (1518), Estado (1521), Hacienda (1523), o por territorios: Aragón (1494), Indias (1525), Italia (1555), Flandes (1555) y Portugal (1582), que tenían también funciones gubernativas (ejecutivas) y judiciales, aunque recientemente se matiza esta distinción con la afirmación de que todos implicaron la instauración de la jurisdicción del rey sobre la del territorio o reino y su jerarquización se daba según otros criterios, como la supremacía de los castellanos 58 .

A nivel territorial se dió la misma especialización y mezcla de funciones en los virreyes, corregidores, gobernadores políticos militares y superintendentes, formándose con el paso del tiempo administraciones sectoriales: diplomática (embajadores, cónsules), militar (capitanes generales, gobernadores de armas, capitanes a guerra, oficiales del sueldo y provisión), hacendística (tesoreros, administradores, superintendentes), gubernativa y judicial (corregidores, alcaldes mayores, gobernadores políticomilitares), aunque se diversificaron las escribanías: gobierno, cámara (justicia), guerra, rentas.

Casi todos los órganos de gobierno y justicia tenían una estructura parecida, como era su división en salas en lo que se refería al proceso de decisión (salas de gobierno y justicia), y una articulación en relatores y escribanos, para el trámite de los documentos, que también se especializaron por la materia: gobierno, cámara, justicia, guerra, rentas.

57 José Javier RUIZ IBÁÑEZ, Las dos caras de Jano. Monarquía, ciudad e individuo. Murcia, 1588-1648, Murcia, 1995, 33-34.

58 Manuel RIVERO RODRÍGUEZ, "El Consejo de Italia y la territorialización de la monarquía (1554-1600)", Felipe II y el Mediterráneo, Ernest BELENGUER CEBRIÀ, coordinador, Madrid, 1999, v. 3, 97-113. 
Los fondos documentales de la administración central o real de la época de los Austrias, en los que podemos encontrar los documentos referentes al gobierno de cada uno de los reinos de la Monarquía hispánica, están dispersos y fraccionados entre diversos archivos históricos de la Administración Civil (ACA, AGS, AHN) y de la Administración Militar: Archivo General del Ejército de Tierra, en Segovia, y Archivo General de Marina, en Viso del Marqués, Ciudad Real.

\subsection{Casa Real.}

En la Corte se distinguía la Casa Real, con algún órgano dependiente especializado, como la Audiencia de Descargos, la Junta de Obras y Bosques y la Junta del Bureau ${ }^{59}$. La primera se ocupaba de los descargos de conciencia de los reyes, y la segunda administraba desde 1545 el patrimonio privado de los reyes, ocupándose de la conservación de palacios, casas y sitios reales, para lo que contaba con diversos oficiales: veedores, intendentes, mayordomos ${ }^{60}$. Era también tribunal para lo relativo a personal y asuntos de caza, pesca y leña, en competencia con la Junta del Bureau, que era juzgado de criados, soldados y proveedores. Hay documentación de la Casa Real y de las juntas dependientes en el Archivo del Real Palacio, en el $\mathrm{AGS}^{61}$ y en el AHN.

El siguiente nivel de la administración central sería el de los consejos y juntas, encabezados por los consejos de Estado y de Castilla.

\subsection{Consejo de Estado.}

El Consejo de Estado, del que dependían las embajadas o legaciones y las negociaciones diplomáticas, era un órgano de marcado carácter consultivo, con una jurisdicción más amplia que la de los demás, pues se extendía a toda la Monarquía hispánica, y cuya presidencia ocupaba el rey, de lo que se deriva la importancia de sus secretarios, que eran quienes en la práctica ejercían la presidencia, para lo que despachaban directamente con el rey. Creado (1521) a principios del reinado de Carlos I con una secretaría, Felipe II instituyó una

59 Juan Francisco BALTAR RODRÍGUEZ, Las juntas de gobierno en la Monarquía Hispánica (ss. XVI-XVII), Madrid, 1998.

60 Ángel DE LA PLAZA BORES, Archivo General de Simancas. Guía del investigador, Madrid 1980, 173.

61 Isabel AGUIRRE LANDA, "Viejos y nuevos documentos en torno a Carlos V", en Juan Luis CASTELLANO CASTELLANO/Francisco SÁNCHEZ-MONTES GONZÁLEZ (eds.), Carlos V. Europeísmo y universalidad, Madrid, 2001, 35-46. 
nueva secretaría en 1567 (una se ocupaba de los asuntos de Italia y el Mediterráneo y otra de los asuntos del Norte de Europa), a las que Felipe IV añadió una tercera, entre 1630-1641 y 1648-1661, para los negocios de la Península Ibérica e Islas adyacentes. En él se trataban los asuntos de reputación: diplomáticos y consulares. Su documentación está dividida entre el AGS y el AHN. La Sección de Estado del AHN engloba documentación de otros órganos, relacionados con el Consejo de Estado, como fueron la Junta de Estado y los consejos de Italia y Flandes, conocidos también como consejos provinciales ${ }^{62}$.

2.3. Consejo de Castilla.

El Consejo de Castilla, o Consejo Real por antonomasia, fue una institución más próxima a los territorios, como los reinos de Castilla y León, que el Consejo de Estado. Surgió en una época (el reinado de Juan I, concretamente en 1385) en que el rey tuvo que aceptar el asesoramiento de representantes de todos los estamentos (la nobleza, el clero y las ciudades, las llamadas dignidades y provincias), aunque desde ese propio reinado empezó la tendencia a sustituir a los representantes de dignidades y provincias por letrados procedentes de la pequeña nobleza de las ciudades y preparados para aplicar el derecho a favor de la monarquía, por medio de la recepción e instrumentación del Derecho romano o común. Fueron los Reyes Católicos quienes tras vencer a la alta nobleza en la Guerra de Sucesión, consiguieron consolidar esta instrumentación absolutista del Consejo Real (1480), relegando a los estamentos. Además de ejercer la justicia en última instancia, el Consejo detentaba el gobierno, tanto político (a través de la censura y la ejecución) como económico. Los procesos judiciales se tramitaban ante los escribanos del consejo o escribanos de cámara, mientras que los asuntos de gobierno (expedientes o autos de gobierno) eran gestionados por los secretarios. Los consejeros y secretarios libraban con los reyes por cámara (es decir, directamente) o por expediente, es decir, por escrito ${ }^{63}$.

Sus documentos están también divididos entre el AGS (Sección de Consejo Real) y el AHN (Sección de Consejos Suprimidos, documentación del Consejo Real), aunque en uno y otro hay que tener en cuenta otra sección, la del Registro General del Sello.

$62 \mathrm{M}^{\mathrm{a}}$ Pilar CASTRO MARTOS, op.cit., cfr. 128-131.

63 Luis G. DE VALDEAVELLANO, Curso de Historia de las Instituciones españolas, Madrid, 1977, 460. 


\subsection{Consejo de la Cámara de Castilla.}

Por cámara se tramitaban desde la Baja Edad Media los asuntos de gracia, merced y patronato, pero fue separada la Cámara de Castilla (1518) del Consejo, aunque sus consejeros, o camaristas, cuatro, lo eran también del Consejo de Castilla, al que fue anexionada entre 1715 y 1717. Las secretarías de la Cámara fueron primero dos (1571), la de Cámara y la de Patronato y Órdenes Militares ${ }^{64}$, y después tres (1588): Gracia, Justicia y Patronato. En 1588 recibió este Consejo de Cámara su primera Instrucción u ordenanza. La Cámara representa lo más característico del absolutismo monárquico: su no sujeción al Derecho o su arbitrariedad, que se manifestó en nombramientos de oficios de justicia, concesiones de títulos nobiliarios, naturalizaciones de extranjeros y legitimaciones o habilitaciones de hijos naturales, facultades para fundar mayorazgos y para disponer de bienes vinculados, indultos. Su documentación se divide entre el AGS (ss. XVI y XVII) y el AHN (siglos XVII y XVIII).

De las competencias de la Cámara deriva también gran parte de la documentación de las secciones Patronato Real y Patronato Eclesiástico del AGS, formadas en el siglo XVI por el archivero Diego de Ayala en una labor selectiva, con la idea de servir a la defensa de los intereses y derechos de la Corona, entre los cuales el de Patronato era uno de los más discutidos y disputados. Contienen, por ejemplo, mercedes antiguas, memoriales dirigidos a la Cámara y al Consejo Real, bulas de provisión de obispados, documentos relativos a la organización de las Cortes, consultas de nombramientos de oficios, libros de Cédulas (no pasaban por el Registro del Sello), libros de Relación.

En la sección de Consejo de Cámara de Castilla, en lo que se refiere a las funciones de gracia y justicia y régimen interior de su Secretaría de Gracia y Justicia, pueden enumerarse las siguientes series ${ }^{65}$ :

Libros generales o registros de cédulas reales y despachos de mercedes o cedularios.

Libros misivos, en los que se registraban noblezas e hidalguías.

Libros de Navarra: del gobierno político de Navarra, con despachos del virrey (1522-1830).

Libros de cortes.

64 Ángel DE LA PLAZA BORES, ob.cit., 15.

65 Ma Jesús ÁLVAREZ-COCA GONZÁLEZ, "La Cámara de Castilla: Secretaría de Gracia y Justicia”, Cuadernos de Historia Moderna. 15 (1994). 286-288. 
Libros de plazas: 16 libros de plazas de asiento de consejos, chancillerías y audiencias (1606-1833).

Libros de justicia, o de plazas de justicia (1595-1830).

Libros de información de oficios.

Libros de corregimientos (1568-1833).

Libros de residencias de corregidores ${ }^{66}$.

Libros de títulos (nobiliarios y administrativos) o relación.

Libros de paso (por la frontera).

Libros de despachos de la Junta de Vestir la casa, desde 1668, pues su secretario era el Presidente de la Cámara.

2.5. Consejo de Órdenes.

Del Consejo Real derivaron todos los Consejos. Uno muy importante para todos los reinos de la Monarquía es, sin duda, el de Órdenes, dada la extensión de los territorios de los institutos religiosos militares en ellos. En este caso, es en el AHN donde se conserva principalmente su documentación. La Sección de Órdenes militares, también sujeta recientemente a un proceso de identificación (Álvarez-Coca: 1996 y 1999), es en realidad un grupo de fondos documentales, pues abarca el fondo del Consejo de Órdenes, creado por los Reyes Católicos en 1495, que tuvo un Registro del Sello propio a partir del siglo XVI; los fondos de los monasterios y conventos, creados con las Órdenes desde mediados del siglo XII, divididos por órdenes castellanas (Calatrava, Alcántara y Santiago) y no castellanas (San Juan, el Temple, Santo Sepulcro, Montesa). El Consejo de Órdenes, por otra parte, que al igual que otros consejos tenía secretarios (uno por cada orden castellana) y escribanos de cámara o de justicia, contaba con un archivo en Toledo para las pruebas inconclusas de limpieza de sangre, también englobado en este grupo de fondos.

2.6. Consejo de Inquisición.

El Consejo de la Inquisición, conocido también como la Suprema, era otra institución importante de la Corte o Administración central, pues era el órgano consultivo y judicial para los asuntos relacionados con la ortodoxia de la fe de la Monarquía Católica ${ }^{67}$. De este Consejo dependían los tribunales

66 Ma Jesús ÁlVAREZ-COCA GONZÁLEZ, “La Cámara de Castilla...”, ob.cit., 1992, 2-7.

67 José MARTÍNEZ MILLÁN, La Hacienda de la Inquisición (1478-1700), Madrid, 1984, 9-12. Natividad MORENO GARBAYO, Catálogo de alegaciones fiscales (Archivo 
diocesanos. Es el AHN el que conserva su documentación, que procede del Consejo y de sus secretarías (Castilla y Aragón), compuesta por consultas, correspondencia, memoriales, informes, procesos judiciales, expedientes, dictámenes fiscales, licencias de absolución, etc, de los siglos XV al XIX.

Hay varios tipos documentales que se registraban en los protocolos notariales en relación a estos consejos reales, como eran los documentos de inicio y ejecución del trámite: poderes otorgados a favor de abogados y procuradores para demandas y querellas ante el Consejo, renuncias de regidurías, juradurías, escribanías, y poderes a ante la Cámara; autos de posesión de señoríos jurisdiccionales, autos de recepción de provisiones y cédulas de los consejos mencionados que se adjuntaban a las escrituras notariales de enajenación de bienes vinculados, etc.

\section{3.- Conclusiones}

La evolución histórca de cancillerías y consejos reales puede estudiarse a través de su producción documental y de su conservación archivística. La disposición de esta última, como si se tratara de un yacimiento arqueológico, nos aproxima a las relaciones establecidas entre cancillerías y consejos reales y los patronatos y patrimonios reales, nobiliarios, eclesiásticos y municipales, además de enriquecernos con una explicación racional de la dispersión de su producción documental.

El notariado bajomedieval y altomoderno, por otra parte, puede ser considerado como una prolongación de las cancillerías en el territorio. Pensamos en él como el conjunto de escribanías o notarías que se establecen en los reinos y en las poblaciones concretas. Cancillerías y consejos reales y escribanías locales caracterizarían una administración poco desarrollada, dirigida por las curias o cortes reales, aunque posteriormente se articuló más complejamente (consejos reales, contadurías, juntas).

Los registros de escrituras públicas de ciudades, villas y lugares fueron utilizados por la población para recibir, hacer ejecutar y testimoniar determinadas disposiciones reales, además de hacer contratos y declaraciones privadas.

Tanto la documentación cancilleresca como la notarial contiene numerosos testimonios de privilegios, honores y distinciones, cuya memoria se hace conservar, en unos casos para defender el patronato y el patrimonio

Histórico Nacional, Sección de Inquisición), Madrid, 1977. Juan BLÁZQUEZ MIGUEL, "Catálogo de los procesos inquisitoriales del Tribunal del Santo Oficio de Murcia", en Murgetana, 74 (1987), 5-109. 
real, en otros los de la nobleza y otros grupos privilegiados. La agrupación archivística de los documentos de Patronato Real, por ejemplo, se realizó en forma de colección, hoy en día considerada facticia, es decir, sin una clasificación coherente, pues interesaba la conservación de estos documentos para fines particulares, patrimoniales, no para que accedieran a ellos otras personas ajenas al monarca y su familia o sus oficiales de mayor confianza. Como máximo la descripción de estos documentos, que estaban frecuentemente instalados en arcas o arquetas, se limitaba a una relación poco sistematizada ${ }^{68}$, puesto que tampoco el volumen de esta documentación fue muy grande, hasta que su crecimiento se hizo mucho mayor en los reinados de Carlos I y Felipe II ${ }^{69}$.

68 Jaume RIERA Y SANS, Catálogo de memoriales e inventarios (siglos XIV-XIX). Archivo de la Corona de Aragón, Madrid, 1999.

69 Luis MARTÍNEZ GARCÍA, "El Archivo de Simancas en el Antiguo Régimen: secreto, patrimonio, justificación y legitimidad real”, Boletín de la Asociación Nacional de Archiveros, Bibliotecarios, Arqueólogos y Documentalistas, 2 (1999), 77-116. 